DOI 10.31418/2177-2770.2019.v11.c3.p04-07 | ISSN 2177-2770

Licenciado sob uma Licença Creative Commons

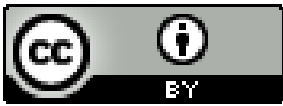

\title{
APRESENTAÇÃO | CADERNO TEMÁTICO: "SABER-FAZER EM CIÊNCIAS \& TECNOLOGIAS - TRAJETÓRIAS AFRODIASPÓRICAS"
}

PRESENTATION

PRESENTACIÓN

PRÉSENTATION

Zuleika Stefânia Sabino Roque

Eliane Costa Santos ${ }^{2}$

Gustavo Henrique Araújo Forde ${ }^{3}$

\footnotetext{
${ }^{1}$ Possui licenciatura e bacharelado em História (UNIVAP), licenciatura em Pedagogia (UNITAU), Mestre e Doutora em História (PUC/SP), Pós Doutoranda junto ao Centro de Matemática Computação e Cognição, Programa de Neurociência e Cognição da Universidade Federal do ABC, integrante do Grupo de Estudos de Aspectos Neuropsiquiátricos e Motricidade (GEANM). Afiliada à ABPN. Professora da Educação Básica Rede Pública Estadual de São Paulo.
}

2 Doutora em Educação/FE-USP, Mestra em Educação Matemática/PUC-SP. Licenciada em Matemática/UFSC. Docente da UNILAB- Universidade da Integração Internacional da Lusofonia AfroBrasileira/Malês-BA. Coordenadora do GIPEm- Grupo Interdisciplinar de Estudo e Pesquisa em Etnomatemática/UNILAB. Membro do GEPEm/FE/USP. Professora convidada do Mestrado em Educação da ULAN/Angola. Pesquisadora em Etnomatemática, Racismos e Decolonidade do Saber nas Culturas africanas e quilombolas.

${ }^{3}$ Doutor em Educação e professor adjunto do Centro de Educação da Universidade Federal do Espírito Santo (Ufes), onde atua na área Educação das Relações Étnico-Raciais. É pesquisador do Núcleo Capixaba de Pesquisa em História da Educação (NUCAPHE - Ufes e, do Núcleo de Estudos AfroBrasileiros (NEAB - Ufes). Desenvolve estudos e pesquisas em afrodescendência e relações étnicoraciais na educação, com interesse especial nos campos da história da educação da população negra, do movimento negro e da matemática. Atualmente é Pró-Reitor de Assuntos Estudantis e Cidadania da Ufes.

Revista da ABPN • v. 11, Ed. Especial - Caderno Temático: "Saber-fazer em Ciências \& Tecnologias - Trajetórias Afrodiaspóricas" • dezembro de 2019, p.4-7 
Em “Saber-Fazer” em Ciências \& Tecnologias- Trajetórias Afrodiaspóricas,

a Revista da Associação Brasileira de Pesquisadores Negras e Negros, visa uma trajetória insubordinada a aproximação da ciência produzida na academia com as práticas referenciadas nas matrizes culturais africanas e diaspórica afro-brasileiras.

Pluralizar "ciência" e "tecnologia" tem para nós a significância do conhecimento acumulado pela humanidade, bem como das tecnologias datadas antes da colonialidade do saber, compreendendo a necessidade de fazer eclodir os marcos silenciados de muitas produções acadêmicas de africanos e diaspóricos.

Saber-Fazer é demonstrar domínio de ciência e de tecnologia, dos mestres dos saberes, das comunidades além-mar. Portanto nesse sentido, foram reunidas neste Dossiê da ABPN a trajetória de alguns pesquisadores que têm colaborado das mais diversas formas para inserir temáticas que nos são caras e consolidar a pesquisa no campo de Africanidades em C\&T, como também, dos que tratam da produção realizada neste campo, sinalizando que o enfrentamento do racismo com diferentes estratégias.

Portanto, os artigos apontam desde a acolhida do estudante da Educação Básica, que sofre diferentes formas de racismo e violência simbólica mediante a toda carga eurocêntrica opressora na qual foi cunhada nosso sistema educacional, tendo a perspectiva de uma quebra de paradigmas a partir de um currículo de ciências afroreferenciado permitindo importantes reflexões identitárias, como é o caso da representatividade, ou melhor dizendo, da falta dela das representatividades em nossos livros didáticos, que mesmo após anos da alteração da LDB e promulgação da Lei 10.639/03 ainda segue reforçando narrativas únicas e que promovem a exclusão da maioria da nossa população; perpassando por uma discussão pertinente e delicada que é sobre o cabelo. Longe de ser questão estética, estamos tratando do rompimento de padrões. Tais discussões são realizadas nas contribuições de Caio Ricardo Faiad da Silva, Gabriela Aparecida de Lima, Daisy de Brito Rezende, com o artigo intitulado "a representação étnico-racial nos cadernos de ciências da natureza das redes municipal e estadual de São Paulo" e no artigo de Marcia Narcizo Borges, "A Química nos cabelos: relato de experiência de ensino CTS visando uma educação antirracista".

Adentrando ao Ensino Superior, luta contínua nossa de ocupação cada vez maior de nosso povo que tem paulatinamente avançado fruto do movimento educador negro, 
que forma e transforma, fazendo da Universidade um lugar de fato universal, contamos com três contribuições, sendo uma delas relacionada ao acesso e permanência de estudantes quilombolas e outras duas que utilizam uma concepção de currículo que tem a cultura como escopo. Em “Acesso e permanência na Educação Superior: percepções de estudantes quilombolas na Baixada Maranhense" de autoria de Dinalva Pereira Goncalves, Evandicleia Ferreira De Carvalho, Ana Patricia Dos Santos Sodré, nos elucidam sobre o cotidiano de estudantes cotistas, revelando perfil desses estudantes e desmistificando práticas discursivas que insistem em estereotipar os estudantes oriundos da educação pública, principalmente os que fazem uso de ações afirmativas. Em “(Etno) Ciência africana: uma epistemologia a partir do pensamento dos Dogons" de Elcimar Simão Martins, Alexandrino Moreira Lopes, Ianes Augusto Cá, Jorge Andrade, joga-se luzes sobre os povos Dogons e amplia-se a perspectiva sobre o que (des)conhecemos da África, na tríade escrevivênciaempoderamento e resistência uma experiência decolonial promove pertinente discussão. $\mathrm{Na}$ mesma esteira, de uma abordagem afroreferenciada e comprometida com a revelação de Áfricas, o Egito é apresentado em uma perspectiva matemática, sendo lido a partir de uma fonte histórica que é o papiro, elucida-se sobre o pensamento matemático, mais especificamente dizendo, o cálculo algébrico em períodos anteriores à Era Cristã, colocando um movimento pendular na História que tende a insistir na ocidentalização da ciência. Gustavo Henrique Araújo Forde em "Matrizes negroafricanas do cálculo algébrico: o conhecimento matemático no papiro Ahmes" de forma interdisciplinar aproxima tanto a História da Matemática, quanto o Ocidente do Oriente.

A ciência, o saber-fazer permeado por sons e vozes, ritmos e luta contra opressões de gênero e geração, são apresentados através do Maracatu e da Capoeira, sendo a memória o eixo condutor dessas formas de luta. Em "Baque mulher e suas raízes na memória cultural/religiosa do Maracatu Nação: uma análise de performance”, de Viviane de Faria Moreira, a performance de mulheres, evidenciam o quão vital o feminismo negro nos é as pautas legítimas, como dizia Lélia Gonzalez "Sabe qual é o negro mais bonito do mundo? É aquele que tem consciência de suas raízes, de suas origens culturais. É aquele que tem a atitude de quem sabe que é ele mesmo". A oralidade é uma herança capaz de conectarmos à nossa ancestralidade e traduzir 
conhecimentos que ainda estão longe de serem inventariados na lente reduzida e eurocêntrica. Mais do que roda, mais do que dança, mais do que luta, um modo de ser e estar no cotidiano, esquivando, gingando e lutando sim, contra o esquecimento, pois a função da história é lembrar aquilo que pode ou não ser foco de esquecimento social, em "Ensaio sobre a arte da Escuta: Mestres de Capoeira e Acadêmicos, experiências em jogo", Zuleika Sabino aponta o quanto a Capoeira, sendo uma prática forjada na realidade brasileira de tempos de escravidão e que se mantém nos dias de hoje, é uma manifestação da brasilidade que pode ser analisada sob diferentes prismas. No presente estudo, pretende-se transcender às representações da capoeira como objeto de investigação da história, cultura, esporte, folclore, e abraçar novas representações.

Por fim, seguimos com saberes e fazeres a serem documentados em diferentes espaços, seja na escola, na universidade, na rua, na roda, nos livros, e nada mais contemporâneo do que uma forma de luta em meio virtual, o movimento negro se educa, se re-educa, se re-inventa, precisamos estar atentos a toda a sua vitalidade. A sociedade em rede está consolidada e o antirracismo tem atuado também neste campo, como nos demonstra Sandro Lopes dos Santos e Vera Lúcia Nojima em seu artigo "Marca da campanha 21 Dias de Ativismo contra o Racismo: uma expressão do Design Afirmativo".

Assim, esses diferentes autores e autoras negras da área de ciências e tecnologias contribuem para apreendermos os processos de resistência a partir das intervenções do pensamento negro desde séculos a.c., nos potencializando para pensarmos em estratégias de transformar a realidade no tempo atual.

Boa leitura! 